\title{
Review of Coveralls, Gowns, and their Use as Part of Personal Protective Equipment (PPE KIT) for Effective Protection of Healthcare Workers in India in COVID-19
}

\author{
Raag Setia ${ }^{\text {a b }}$, Anita Kamra Verma a (iD \\ a Nanobiotech Lab, Kirori Mal College, University of Delhi, Delhi-110007

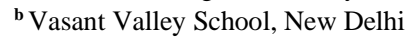

\begin{abstract}
Healthcare Workers (HCWs) and public health professionals are playing a pivotal role in containing COVID-19. Personal Protective Equipment (PPEs) are a critical component in the hierarchy of primary infection controls to "break the chain of infection' to protect patients, HCW's, and public. As SARS-CoV-2 is highly contagious, and vaccine and prophylactics not yet available, understanding correct PPE usage is imperative. This study aims to: understand purpose, use, and quality standards of body-coveralls and gowns and how to use PPE's for effective protection in COVID 19 in India. Types of PPE's in healthcare, their purposes, materials used, and properties were reviewed. Gowns and Body-coveralls classification and standards in Europe, USA and India were studied. While current stipulated test standards for coveralls in India are lower, as routine use of reusable gowns made of woven fabrics is more common in India, one could hypothesize that these coveralls provide a higher level of protection. As per current understanding of mode(s) of transmission of SARS-CoV-2 a properly fitted N95 respirator; goggles and splash resistant face shield; gloves; and single-use full body-coverall/gown preferably resistant to Synthetic Blood Penetration under pressure and made of non-woven Laminated SMS (Spunbond-Meltblown-Spunbond) or Non Laminated SSMMS fabrics are advisable depending upon anticipated level of exposure. HCW's should educated about transmission risks, correct principles of infection control, functional purpose of PPE's and must be conscious that PPE's alone will not protect them. They must follow good practices of how to wear (don) and how to remove (doff) and ensure that they do not inadvertently contaminate their clothing/skin and self-inoculate.
\end{abstract}

KEYWORDS: Personal Protective Equipment (PPEs), COVID-19, Healthcare Workers (HCWs)

Correspondence: Anita Kamra Verma, Nanobiotech Lab, Kirori Mal College, University of Delhi, Delhi 110007, India. Email: $\underline{\text { akverma@kmc.du.ac.in }}$

Copyright $\odot 2020$ Setia R \& Verma AK. This is an open access article distributed under the Creative Commons Attribution 4.0 International, which permits unrestricted use, distribution, and reproduction in any medium, provided the original work is properly cited.

\section{INTRODUCTION}

Personal Protective Equipment (PPEs) have become important during COVID-19 pandemic due to the highly contagious nature and virulence of the virus and insufficient treatment modalities. PPE's are used in many settings - in industry, against pollutants, in sports, and in healthcare. PPEs have been used time and again during epidemics and pandemics, and are in routine use as a critical component in the hierarchy of controls as part of infection control to protect healthcare workers (HCW's), patients and others from health-related risks, and exposure to infections. The earliest forms of PPEs were used for the Black Death epidemic in the $14^{\text {th }}$ Century, though we now know that they were ineffective.

HCW's are in the combat zone when treating communicable diseases and risk getting infections ${ }^{[1][2]}$ and various infection control strategies are used for protection. The rapid spread of COVID-19, and reports of many HCW's including doctors and nurses getting infected while treating patients, led to the realization that the routine PPE's and practices are not sufficient. There were reports of HCW's getting infected despite using PPE's specifically for COVID-19, and discomfort of PPE's hindering ability to work, leading to noncompliance $^{[3][4]}$.

As countless HCW's were affected there developed need for suitable PPEs in large quantities. Hospitals and governments did not have much prior knowledge/experience of the types of suitable PPEs, nor stocks/supply-chains ${ }^{[5]}$. This research is important as need for suitable PPE's in large numbers continues and though 
production has increased there are doubts about quality/efficacy. Globally many manufacturers repurposed facilities to produce PPEs. However, they lacked proper knowledge of the design, materials to be used, quality standards and regulations. India lacked organized PPE production before February/March $2020^{[6]}$, and not enough knowledge or understanding about them. Due to the huge demand and Government's encouragement, several producers started manufacturing or supply of PPE's. However, there are many questions on what PPE's are, which are suitable, are they safe, can they be reused, be made more comfortable and cost-effective, and what is the impact on the environment?

Research was undertaken on PPE's used in healthcare and their utility. To understand the type of PPE's required for protection against the SARS-CoV-2- the virus causing COVID-19, research was done to understand mode of spread. Type of materials used for making PPE suitable to protect against COVID-19, and knowhow of manufacturing details of the body-coverall was researched. Study on the quality standards, testing methods, and Governmental guidelines were done. Materials used for making were collected, some tests performed on them and on the body-coverall. A survey was undertaken to collect feedback from healthcare and other frontline workers, to help understand type of PPE's used, difficulties faced, and preferences or needs of the frontline workers.

Governments and manufactures are gaining better understanding from research previously conducted, and from standards already in place in the USA/EU. The Indian government and industry are establishing quality standards and innovating to find suitable, cost-effective solutions for use in India. By collecting information from various reliable sources, information will be provided to aid government and industry in producing appropriate costeffective PPEs for use in India and elsewhere

The results from this study will prepare the HCWs and Healthcare administrators protect themselves while taking care of those infected, or suspected to be infected by SARS-CoV-2. It may help manufacturers produce comfortable cost-effective body-coverall or gowns meeting required quality standards.

\section{MATERIALS AND METHODS \\ Study design \\ Strategy for Search}

Online search for articles and papers on 'PPE's used in Healthcare' 'quality standards and testing of gowns and coveralls', 'mode of spread of SARS-CoV-2' 'Government guidelines for PPE' 'materials used for gowns / coveralls' was done. Articles, papers, notifications from sites such as CDC, FDA, Ministry of Health and Family Welfare and other reliable sources were shortlisted. Study Selection

Epidemiological, Clinical, and laboratory-based studies done globally have been included in the review. The emphasis of this methodical review was regarding use of PPE for prevention of infectious diseases. Consequently, we specifically involved reports that examined use of overalls, facemask, and respirator for HCW's, with or without other PPE. We have considered only those studies relevant to PPE for review in this article. To better understand PPE's, their uses, and the suitable types to be used in the COVID-19 pandemic, an analysis of articles and scientific papers was undertaken. Latest understanding of modes of spread of SARS-VoV-2 was researched. Information was collated from a variety of sources and inferences were made. Also, professionals involved in the field of production or study of PPEs were interviewed to understand the types of PPEs used in healthcare, need for PPE's during COVID-19 pandemic, and types of PPEs required to protect from the virus. Research was undertaken to gain knowledge about the different materials used for making PPEs, specifically Body-coveralls. Research on the quality standards was carried out to understand the required level of protection against SARSCOV-2 and other viruses. A study of some of the tests prescribed to achieve the quality standards was also done. A detailed study of guidelines and notifications issued by the Government of India was done.

\section{Experimentation}

Samples of different materials were collected and visit to a factory producing Body-coveralls organized. A thorough evaluation of the step-by-step procedure, functioning of testing machines was conducted. Raw material (fabric) samples, and samples taken from manufactured Bodycoverall ${ }^{[7]}$ were tested. Thickness, GSM, hydrophobic property, hydrostatic pressure resistance and synthetic blood penetration were tested using various equipmentVernier Caliper, GSM Cutter, weighing scale, hydrostatic pressure tester, Synthetic Blood Penetration Tester, and synthetic blood.

The Test Procedure under IS 16546- Synthetic Blood Penetration Test (Procedure C) (Same as ISO 16603:2003 Level 3) was done.

The body-coverall (or material) was kept for conditioning at a temperature of $21^{\circ} \mathrm{C}(+-5)$ and $\mathrm{RH} 60(+-10)$ for 24 hours. Initially, the body-coverall was inspected particularly at the folds to check that tape covering the seam was intact/adherent. Samples were cut from 6 places of the coverall- three from the body fabric and three from the seams, one each from a straight seam, curvature and the cross seam and then subjected to the Synthetic Blood Penetration Test by fixing to the Penetration Test Cell. Synthetic blood was poured into the chamber and pressure was gradually increased and through the following six stages: i) $0 \mathrm{kPa}$ for 5 minutes, ii) $1.75 \mathrm{kPa}$ for 5 minutes, iii) $3.5 \mathrm{kPa}$ for 5 minutes, iv) $7 \mathrm{kPa}$ for 5 minutes, v) $14 \mathrm{kPa}$ for 5 minutes vi) $20 \mathrm{kPa}$ for 5 minutes. (No leakage up to Level $3(3.5 \mathrm{kPa})$ is Pass).

\section{RESULTS \& DISCUSSION}

There is paucity of data and lack of stringent guidelines along with Standard Operating Procedures (SOPs) regarding PPE issued in most of the hospitals or laboratories or recovery centres. Transmission of infectious agents in healthcare settings require three elements: a source of infectious agents, susceptible host with a portal of entry receptive to the agent, and mode of transmission. Transmission can be- HCW to patients; patients to $\mathrm{HCW}$ and environment or equipment; and environment/equipment to patients or HCW. The Centre for Disease Control and Prevention (CDC) categorizes three primary routes of contact between people and microorganisms in healthcare settings: (i) contact (direct/indirect), (ii) respiratory droplets (iii) airborne droplet nuclei ${ }^{[8]}$. PPE's are used in healthcare to "break 
the chain" of transfer of infection to protect patients and HCW's from infection. Some protect patients, most serve dual purpose, some primarily protect the HCW's where there is a higher risk of exposure- these PPE's are made to meet higher protection standards.

SARS-CoV-2 is highly contagious with modes of transmission not fully understood; highly virulent, debilitating, often fatal; treatment modalities remain uncertain. no vaccine at present nor confirmed prophylactics . As HCW's treating either confirmed or suspected cases are at high risk- understanding of a suitable PPE's and their correct usage is critical to protect them becoming infected, carriers, or inadvertently spreading the infection.

PPE constitute any specialized clothing, device, or appliance that is designed to be worn or held by an individual for protection against one or more health or safety hazards [9][10]. PPE's used in occupational safety, sports, adventure sports, car racing, etc. include helmets, masks, aprons, hazmat suits, gloves, boots, shin-guards, cricket-pads, elbow or knee protectors etc. For particulate air pollution people use suitable face masks with filters. Historically, prevention of spread of infection in healthcare is focused on preventing infection of the patients from the HCW's and environment, starting with practice of washing hands in chlorinated water in 1846 , introduced by Ignaz Semmelweis, a Hungarian physician who focused on antiseptic procedures ${ }^{[11]}$; introduction of asepsis by Joseph Lister in 1880's; masks first used in surgery by Johann Mikulicz, (University of Breslau) who worked with bacteriologist Carl Flügge ${ }^{[12]}$. Adoption of isolation precautions and principles of asepsis by Grancher in a children's hospital in Paris in 1890 to prevent cross infections, eventually led to use of 'Isolation Gowns' to protect HCW's and later as part of Contact Precautions when working with patients known to be infected with pathogens that spread through direct/indirect contact. In World War II US military developed a high-density woven fabric with less than 5 microns between each yarn, coated with a hydrophobic chemical making it water repellant [13][14]. Such gown created a field of 'isolation' and gave protection. However, it had low penetration resistance, water pressure resistance, poor air permeability and deteriorated with washing.

Development of nonwoven fabrics made of extruded fibers of polypropylene, or such material, layered to form a fine mesh-web found application in hygiene, heath care and other areas. Random orientation of the fibers reduces liquid transmission by (i) providing filtering media (ii) reducing the capillary formation ${ }^{[15]}$. Two varieties are Meltblown and Spunbond. In 1976 technology developed to merge/ bond spunbond with meltblown leading to development of a triple-layered fabric of meltblown sandwiched between layers of spunbond with good strength, breathability, and filtration properties against pathogenic bacteria to some extent. Another technology was the development of PTFE (polytetrafluoroethylene) microporous film applied to the outer layer with pores of 0.3 microns allowing breathability but block passage of blood $^{[16]}$.

\section{Gowns and Body-Coveralls}

Gowns are the second-most-used PPE in healthcare, following gloves. HCW's often get exposed to microorganisms carried through biological fluids like blood, body-fluids, and other potentially infectious materials (OPIM) through direct/indirect contact of contaminated body-fluids with non-intact skin, and mucous membranes. Use of appropriate protective clothing creates a barrier to eliminate, reduce contact and droplet exposure- preventing the transfer of microorganisms between patients and HCWs. In healthcare, many types of gowns are used for different purposes, with different materials, design \& protective properties. Not every type offers the level of protection that a HCW needs in a particular level of exposure.

In USA the FDA adopted a standard ANSI/AAMI PB70:2003 for gowns and protective clothing based on barrier protection levels and risk during intended useLevel 1 (for Minimal Risk) Level 2 (Low Risk), Level 3 (Moderate Risk) and Level 4 (high risk) based on tests and performance levels. FDA classifies medical gowns as Surgical Gowns, Surgical Isolation Gowns and NonSurgical gowns based on design/coverage areas and risk level of intended use. Aprons or gowns not fully covering the back with sufficient overlap do not come into these categories. In surgical gowns based on expected area of exposure only the front panel and lower sleeves are considered critical- level of the gown in as per the performance standard of the lower of the two. Other parts of the gown may not have the same level of barrier protection. In Surgical Isolation gowns and Non-surgical gowns all parts of the gown including the seams, except cuff, hems and binding must have the barrier properties of the Level. Non-surgical gowns are used in Minimal or Low Risk of patient isolation situations and Surgical Gowns for moderate to high risk of contamination. While all gowns will offer some level of protection because of the nature of the material, Level 1 to 3 are tested against Liquid challenge using water (AATCC 42 and AATCC 127), Level 4 is tested against Synthetic Blood Penetration and Viral Penetration under pressure (ASTM 1670/1671 tested up to $2 \mathrm{psi}(13.8 \mathrm{kPa})$ ). Surgical Gown Level 4 provides the best protection amongst gowns. NFPA 1999 standard based on resistance to viral penetration under pressure amongst other requirements applies to bodycoveralls/other multi-piece/partial clothing used for emergency use.

In Europe surgical gowns are classified as 'Standard Performance' or 'High Performance' under EN 13795 based on resistance to liquid penetration and resistance to microbial penetration aimed to protect patients. Gowns are not tested for resistance to Synthetic Blood Penetration or Viral Penetration. As PPE (typically coveralls) protect against infectious agents the standard is EN 14126 based on fabric resistance to penetration by synthetic blood and viral penetration under pressure ISO 16603 and ISO 16604 (ranked Class 1 to 6 based on pressure from $0 \mathrm{kPa}$ to 20 $\mathrm{kPa})$

In India, the Bureau of Indian Standards (BIS) classifies Surgical Gowns in 4 levels from Level 0 to 3 under IS 17334:2019. Body-coveralls come under IS 17423:2020 based IS 16546- Synthetic Blood Penetration Test (Procedure C) (Same as ISO 16603:2003 Level / Class 3 $(3.5 \mathrm{kPa}))$. Both fabric and seams are tested. However, at present there is no mandatory test for Viral penetration. 
Table 1 Summarizes groups of PPE

\begin{tabular}{|c|c|c|}
\hline Types of PPE & Purpose & Material/Properties \\
\hline Gloves: & $\begin{array}{l}\text { Protect Hands/protect the patient in case of } \\
\text { surgery/open wounds }\end{array}$ & Nitrile, Latex, Vinyl \\
\hline Gowns/Aprons Coveralls & Protect skin/clothing & \multirow{3}{*}{$\begin{array}{l}\text { Natural or manmade fiber/fabric. } \\
\text { Thickness depends on Grams per } \\
\text { square meter GSM }\end{array}$} \\
\hline i) Patient Gowns & To examine and treat patients & \\
\hline ii) Cover gown for visitors & $\begin{array}{l}\text { Prevent infection to be carried to } \\
\text { patient/room through clothes of visitors }\end{array}$ & \\
\hline $\begin{array}{l}\text { ii) Isolation Gowns (Also called } \\
\text { Non-Surgical } \\
\text { Gowns/Procedural Gowns }\end{array}$ & $\begin{array}{l}\text { Barrier to spread of infection both ways- to } \\
\text { the healthcare worker from the patient or } \\
\text { vice versa }\end{array}$ & $\begin{array}{l}\text { Depending upon risk of exposure to } \\
\text { fluids they are required to meet } \\
\text { different Liquid Barrier Protection } \\
\text { standards and are classified as } \\
\text { AAMI Level } 1 \text { to } 4 \\
\text { Level } 4 \text { Resistant to Synthetic } \\
\text { Blood Penetration and Viral } \\
\text { Penetration. }\end{array}$ \\
\hline $\begin{array}{l}\text { iv)Surgical gowns/Surgical Isolation } \\
\text { gowns }\end{array}$ & $\begin{array}{l}\text { Sterilized to prevent passage of infection to } \\
\text { patient. } \\
\text { Isolation Gowns has liquid barrier protection }\end{array}$ & \\
\hline Protective Gowns/Suits/Coveralls & $\begin{array}{l}\text { Protect the Healthcare Worker when } \\
\text { exposed to Class A infections like SARS, } \\
\text { Ebola, MERS } \\
\text { Provides a higher degree of protection than } \\
\text { the gown }\end{array}$ & $\begin{array}{l}\text { Hooded top and trouser. Can be a } \\
\text { one-piece structure or separate. } \\
\text { Trouser legs and cuffs are tightened }\end{array}$ \\
\hline Surgical Masks & $\begin{array}{l}\text { Protect mouth and nose (Should fully cover } \\
\text { nose and mouth and prevent fluid } \\
\text { penetration) }\end{array}$ & Has Liquid Barrier property \\
\hline $\begin{array}{l}\text { Respirators } \\
\text { (Other versions can be Particulate } \\
\text { respirators and half or full-face } \\
\text { elastomeric respirators) }\end{array}$ & $\begin{array}{l}\text { Protect respiratory tract from airborne } \\
\text { infections agents }\end{array}$ & $\begin{array}{l}\text { Different types of filtration materials } \\
\text { depending upon usage conditions }\end{array}$ \\
\hline $\begin{array}{l}\text { Powered air purifying respirators } \\
\text { (PAPR) }\end{array}$ & $\begin{array}{llll}\begin{array}{l}\text { Protect } \\
\text { infection }\end{array} & \text { from aerosol/airborne } \\
\end{array}$ & $\begin{array}{l}\text { Air pumped through a HEPA filter } \\
\text { into a suit or head-cover. }\end{array}$ \\
\hline Goggles & $\begin{array}{l}\text { Protect Eyes } \\
\text { (Normal glasses/goggles do not protect) }\end{array}$ & $\begin{array}{l}\text { Should Fit snugly over and around } \\
\text { eyes. Preferably anti fog feature. }\end{array}$ \\
\hline Face Shield & Protect face, mouth, nose, and eyes & $\begin{array}{l}\text { Should cover forehead, extend } \\
\text { below chin, and wrap around face }\end{array}$ \\
\hline $\begin{array}{l}\text { Head Covers } \\
\text { Bouffant caps/Surgical Caps/Other } \\
\text { hair covers }\end{array}$ & $\begin{array}{l}\text { Covers Head to Neck } \\
\text { These are used to prevent any hair or } \\
\text { infection from falling onto the patient during } \\
\text { surgery, wound dressing and to protect } \\
\text { healthcare workers head/hair to carry any } \\
\text { infected material out }\end{array}$ & $\begin{array}{l}\text { Allows vapor to pass through but } \\
\text { stops air and bacteria }\end{array}$ \\
\hline Shoe Covers & $\begin{array}{l}\text { Prevent outside contaminants to come into } \\
\text { clean areas and Prevent infection being } \\
\text { carried out from areas where floor may have } \\
\text { been contaminated }\end{array}$ & $\begin{array}{l}\text { Natural or manmade fiber fabric, or } \\
\text { plastic }\end{array}$ \\
\hline
\end{tabular}

Table 2: Comparison between body-coveralls and gowns

\begin{tabular}{|l|l|}
\hline \multicolumn{1}{|c|}{ BODY-COVERALLS } & \multicolumn{1}{c|}{ GOWNS } \\
\hline $\begin{array}{l}\text { Typically provide } 360^{\circ} \text { protection including back, lower leg, } \\
\text { and sometimes head and shoes as well }\end{array}$ & $\begin{array}{l}\text { Do not provide continuous whole-body protection as } \\
\text { possible opening as back and coverage to mid-calf only. } \\
\text { Does not cover head and shoes. }\end{array}$ \\
\hline $\begin{array}{l}\text { Front zipper closure could compromise barrier protection if } \\
\text { suitable zipper not used and covered with a flap. }\end{array}$ & Gives better front chest protection. \\
\hline Not used routinely by HCW & More frequently used by HCW \\
\hline More difficult to wear/take off & Easier to wear/take off \\
\hline Heat stress to wearer more & Less heat stress to wearer \\
\hline $\begin{array}{l}\text { Less likelihood of compliance and more risk of } \\
\text { contamination while doffing if not trained and done suitably. }\end{array}$ & More likelihood of compliance and proper doffing \\
\hline
\end{tabular}


Table 3: Fabrics Tested

\begin{tabular}{|c|c|c|c|}
\hline Sample & GSM & Thickness & $\begin{array}{c}\text { Synthetic Blood Penetration Test } \\
\text { IS 16546 (Procedure C) }\end{array}$ \\
\hline Laminated SMS & 54 & $0.2 \mathrm{~mm}$ & Passed at $3.5 \mathrm{kPa}$ \\
\hline Non-laminated SMS & 80 & $0.32 \mathrm{~mm}$ & Failed at .75 $\mathrm{kPa}$ \\
\hline Laminated SMS & 70 & $0.34 \mathrm{~mm}$ & Passed at $14 \mathrm{kPa}$ \\
\hline Laminated SMS & 80 & $0.38 \mathrm{~mm}$ & Failed at $3.5 \mathrm{kPa}$ in some swatches. \\
\hline Non-laminated & 60 & $0.32 \mathrm{~mm}$ & $\begin{array}{c}\text { Passed } 3.5 \mathrm{kPa} \\
\text { Failed } 14 \mathrm{kPa}\end{array}$ \\
SMMSS (Breathable) & & & Passed upto $20 \mathrm{kPa}$ \\
\hline Laminated SSMMSS & 75 & $0.35 \mathrm{~mm}$ & $\mathrm{P}$
\end{tabular}

It can be seen that resistance to Synthetic Blood Penetration does not depend purely upon GSM /

thickness or lamination of fabrics. Each fabric type and lot should be tested. Hot Seal of seams provides better resistance but is not guaranteed.

Table 4: Seam Tested

\begin{tabular}{|l|l|l|}
\hline $\begin{array}{l}\text { SEAM } \\
\text { PORTION }\end{array}$ & TYPE OF TAPE & $\begin{array}{l}\text { Synthetic Blood } \\
\text { Penetration Test } \\
\text { IS 16546 } \\
\text { (Procedure C) }\end{array}$ \\
\hline Sample A & & \\
\hline Straight & Cold Adhesive & Pass \\
\hline Curved & Cold Adhesive & Fail \\
\hline Cross & Cold Adhesive & Fail \\
\hline Sample B & & \\
\hline Straight & Hot Seal & Pass \\
\hline Curved & Hot Seal & Pass \\
\hline Cross & Hot Seal & Pass \\
\hline Sample C & & \\
\hline Straight & Hot Seal & Pass \\
\hline Curved & Hot Seal & Pass \\
\hline Cross & Hot Seal & Fail \\
\hline
\end{tabular}

COVID-19 is a disease in humans caused by an RNA virus named SARS-CoV-2 (SARS- Severe Acute Respiratory Syndrome), previously unknown beta-coronavirus which is part of a group of viruses called Coronaviruses (CoVs) [17]. Most Coronaviruses are zoonotic (prevalent in some animals likes bats) and few have affected humans in the past ${ }^{[18]}$. Researchers believe that the virus mutated from a previous zoonotic variety and recombined with a human strain, spreading from human to human ${ }^{[19]}$.

The illness can be very severe in some individuals, especially those above 60 , or those with other pre-existing diseases, however, it affects all ages. It is fatal in a certain percentage of patients because of its complications. The disease is very debilitating in many cases and severe symptoms can persist for long time ${ }^{[20]}$.

The dominant mode of transmission is close person-toperson contact with infected individuals via droplets from the respiratory tract. Respiratory droplets spread through nasal discharge, coughing, sneezing, speaking or singing loudly etc. Infection happens by the virion entering through nose or mouth, or the eyes as the lachrymal fluid (tears) drain into the nasal passage. It also spreads indirectly as a person may self-inoculate by touching fomites on contaminated surfaces either by touching droplets from an infected person- and then touching one's own face, mouth or nose. Aerosols (fine droplets) generated in certain hospital procedures stay in the air and cause airborne transmission. Infection through contaminated utensils is also possible ${ }^{[21]}$.
It can affect the gastrointestinal tract and spread through fecal-oral route. It could spread through an infected person's body fluid like saliva, vomit, blood etc. The SARS Cov-2 virion is estimated to be between $60-140 \mathrm{~nm}$ (nanometers) in size. Each respiratory droplet is 5-10 micrometers length potentially containing hundreds or thousands of virus particles ${ }^{[22]}$. The virion is very stable and stay stable on copper- 4 hours, cardboard 24 hours and plastic or steel surfaces for nearly 3 days ${ }^{[23]}$. It is destroyed by using soap and water while iso-propyl alcohol helps sanitize the surfaces.

It is highly contagious and has a reproduction number $\left(\mathrm{R}_{\mathrm{o}}\right)$ between 2.0 and 3.0 $0^{[24]}$. As it is a novel virus, humans have no previous exposure to this or anything similar, hence no inbuilt immunity. As it spreads from one human to another even before a person becomes symptomatic (during the incubation phase), and as $30 \%$ persons infected are themselves asymptomatic, but capable of spreading the disease, it has spread extremely fast. There is no vaccine to protect against the infection, nor any confirmed medication to use prophylactically (to prevent infection). Till a vaccine or suitable prophylactic treatment is found, epidemiological control, containment of the spread, detection, and protection of every person, especially those directly exposed to known or suspected cases is important. Therefore, the role of Personal Protective Equipment and other precautions is essential to the eradication of COVID19.

In India disposable gowns are used usually when the patients are known to be Hep B, C or HIV positive, or in tertiary hospitals in specialized surgeries. Mostly reusable gowns made of woven fabrics are used. Due to frequent washing and autoclaving the fabric deteriorates and these gowns may not protect against liquids or body fluids; in fact, they could soak liquids or other body fluids more easily.

With COVID-19 spreading through droplets and not much known about how long the virus remains viable in the environment, protective clothing made of nonwoven fabrics which have repellency to water offer better protection. Resistance to liquids under pressure, and to Penetration of Synthetic Blood under pressure offers better protection. The stipulated standard IS 17423:2020 is lower than standards in USA/Europe, and resistance to Viral Penetration under pressure is not yet mandated.

As there are no such studies, one presumes that the bodycoverall's design and quality standards under BIS standard IS 17423:2020 offers better protection than a reusable woven-fabric gown where risk of exposure is high; for example in HCW's working with COVID positive or 
suspected patients. It would also be suitable at emergency services and primary health services level.

Users should be made aware that the coverall standard in India does not include testing for viral penetration, hence may not offer the requisite protection against liquids along with high pressure due to leaning, kneeling etc. and should exercise caution even with PPE use.

We want to draw upon the 'Protection Strategy Pyramid' based on US Army CBRN Defence Strategy (Chemical, Biological, Radiological, Nuclear hazards) shared by Dr. Sheshadri R. in an article to suggest suitable protection strategy ${ }^{[25]}$ in the SARS-CoV-2 pandemic

It envisages Sense (threat) based on the increasing number of positive cases of COVID-19. Lab technicians, Doctors other HCWs and other associated frontline workers essentially fall in the category of higher risk as they are directly exposed to persons suspected or confirmed to be infected. Accordingly, HCWs exhibit higher incidence as compared to general population. HCWs could also become source of infection to others and could inadvertently become carriers and spread infection to other patients/ HCWs in their facility or even to their families.

Second aspect of the pyramid is Shape i.e., understanding the threat. The dominant mode of spread of SARS-CoV-2 via the respiratory droplets expelled/dispersed into the environment through nasal discharge, coughing, sneezing, speaking loudly. Infection happens through virions that come in contact with the mucous membrane of the nose, mouth, or eyes. It spreads directly through the air, or indirectly as a person may self-inoculate by touching fomites/surfaces/clothes contaminated by droplets from an infected person. Aerosols (fine droplets) generated in certain hospital procedures in the air could cause airborne transmission through the air.

Third part is Shield i.e., protection from threat. Face covers reduce droplet dispersal and give limited protection. Surgical Masks reduce droplet dispersal and give limited protection. Properly fitted Respirators (N95, equivalent or above) offer protection. Goggles give eye protection Face Shields give added protection but not a substitute for mask. Gloves protect hands, but gloves will be the most contaminated and should be frequently washed/sanitized or changed. Body-coverall or combinations of Gowns, Head-Cover, Shoe-Covers, additional Aprons where required will protect one's exposed skin/hair and clothes, to prevent contamination. PAPR provide additional protection in areas where there is risk of aerosol/airborne transmission. PPE's should be donned in the correct sequence before entering the area with exposure risk. Where patients with COVID-19 are (cohorted) grouped, gloves should be changed between examining patients. When exposed to patients with confirmed/ suspected SARS-CoV-2 infection, PPE which could have got contaminated should be removed and disposed off/suitably disinfected before moving out of the area/coming in contact with others to avoid passing infection to others. Sustain or rather contain the threat is emphasized as an important aspect of the pyramid. Separate COVID areas for suspected cases and confirmed in-patients for isolation; masks for patients where possible; HCWs in COVID wards/COVID designated areas should be restricted from working in non-COVID areas and take all possible precautions not to carry infection to others. Regular testing and screening of HCWs is a must.

\section{Effective Use of PPE's}

Comfort is one of the important characteristics for PPE compliance. The features most likely to impact compliance are movement restriction, time and ease to use or remove, thermal comfort (breathability) and gown fit, besides relating to large-sized users, neck designs and tie closures. PPE's should be designed to be comfortable (thermally and physically) [26] as far as possible without compromising function to ensure better compliance and better protection and should be available across all sizes. Body-coveralls made with fabric that allows water vapor transmission should be preferred, however cost would be higher.

As both gowns and body-coveralls offer contact protection against liquids, administration and HCW's can assess the level of exposure risk in patient interaction and appropriately use single use liquid-resistant gowns of suitable level or body-coveralls as required.

Just having suitable quality PPE's does not guarantee protection. HCW's should be made aware of the modes and risks of transmission, the functional purpose of the PPE, and should be instructed on how to wear (don) and how to remove (doff) to ensure that they do not inadvertently contaminate their clothing or skin and selfinoculate themselves.

When wearing full PPE, care should be taken to ensure that there are no risk of leakage (strike-through) at the interface of the different components of the PPE kit- like the cuffs and the gloves (sleeve should have a thumb loop to ensure the sleeve is not pulled up) and gloves should be worn over the cuff. Due care should be taken to ensure the mask fits properly. The face shield should cover the opening of the face.

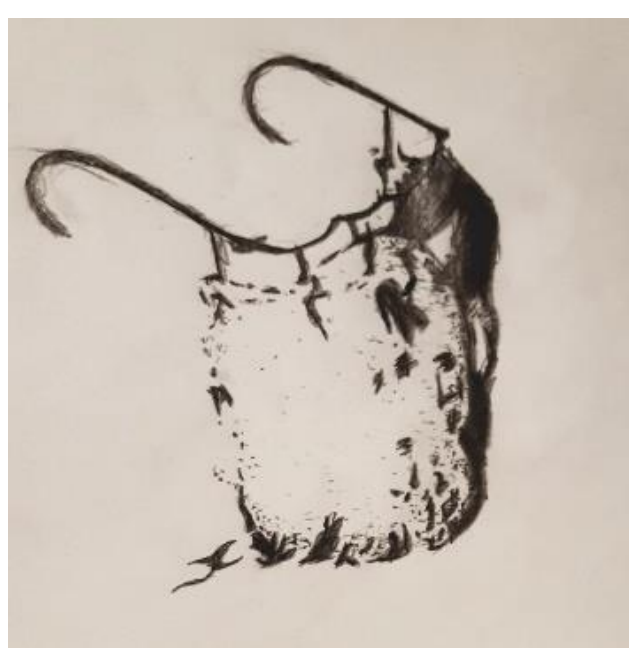

Fig 1. Early Mask

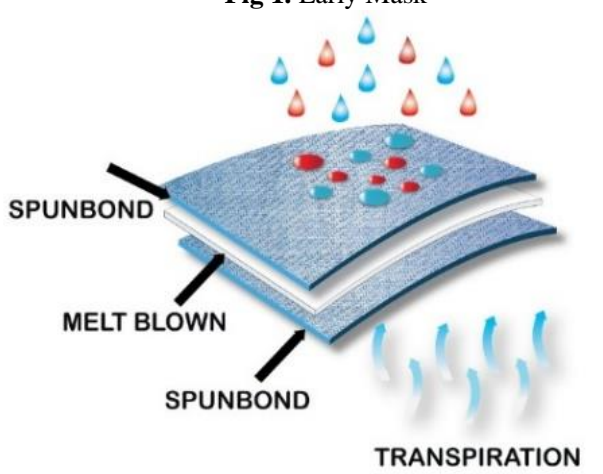

Fig 2. SMS (Spunbond Meltblown Spunbond) Fabric 

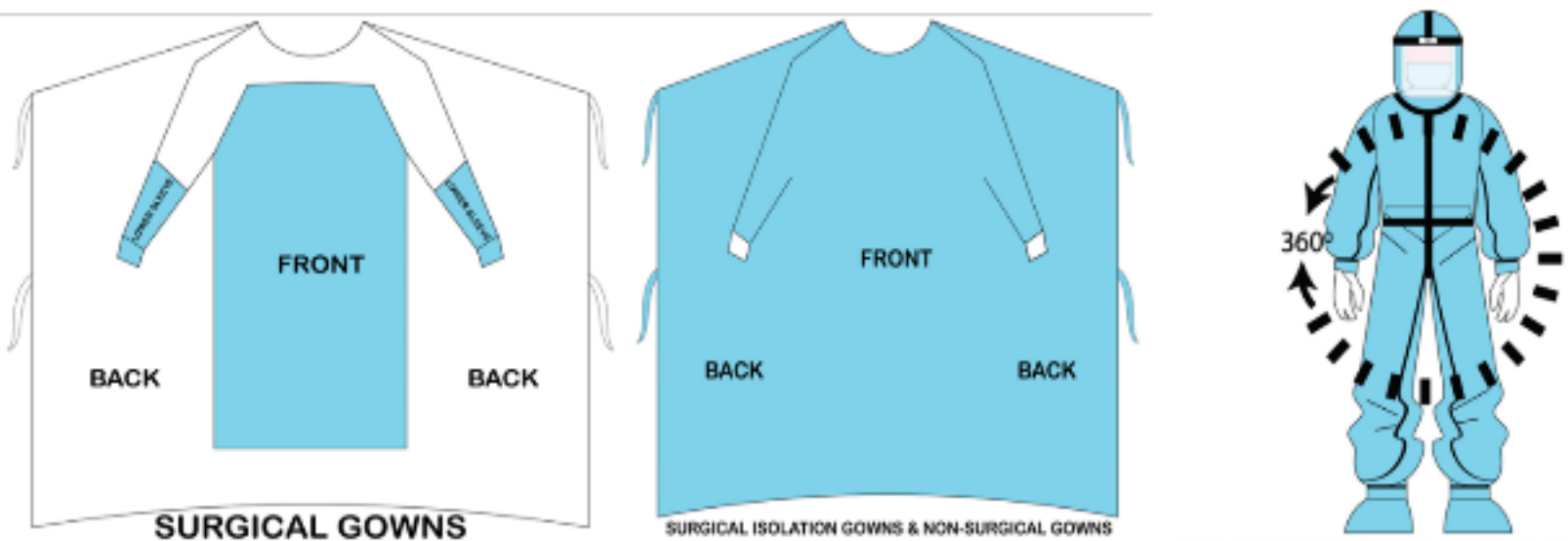

Only front panel and lower sleeves are considered critical All parts of the gown must have the barrier properties ONE PIECE BODY COVER ALL AND OTHER PPE

Fig 3. i) Surgical Gowns, ii) Surgical Isolation Gowns, iii) One-piece Body Coverall
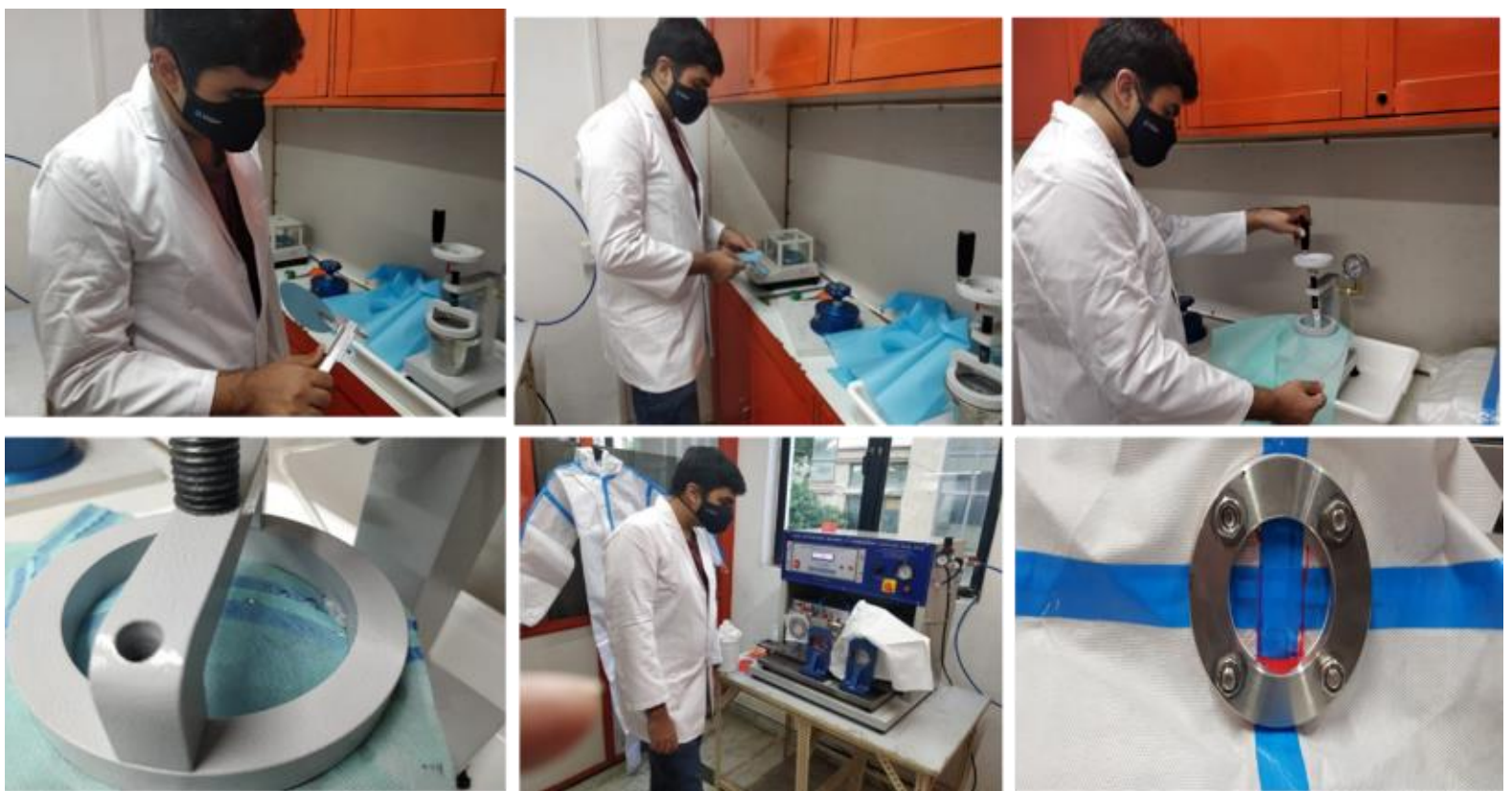

Fig 4. Testing of materials and Full Body-coverall a) Thickness b) GSM c) Hydrostatic d) Hydrostatic Pressure e) Synthetic Blood Penetration Test f) Showing Leakage of Synthetic Blood under pressure

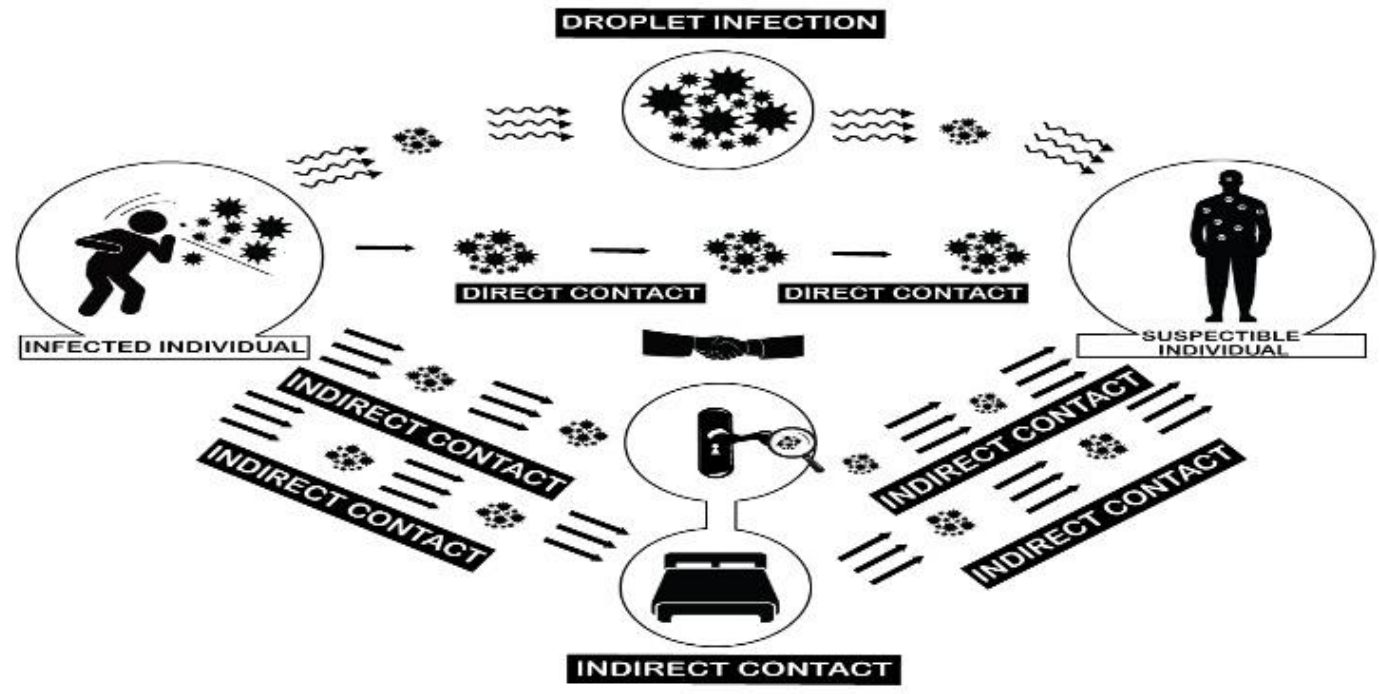

Fig 5. Modes of Transmission of SARS-CoV2 


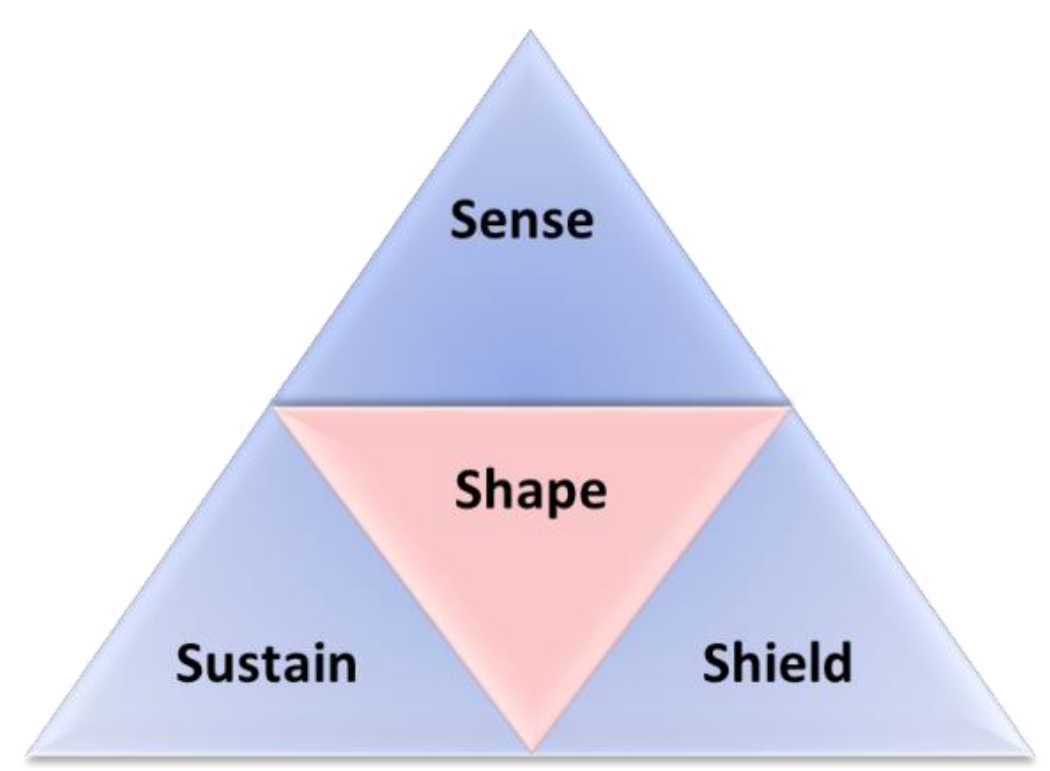

Fig 6. Protection Strategy Pyramid

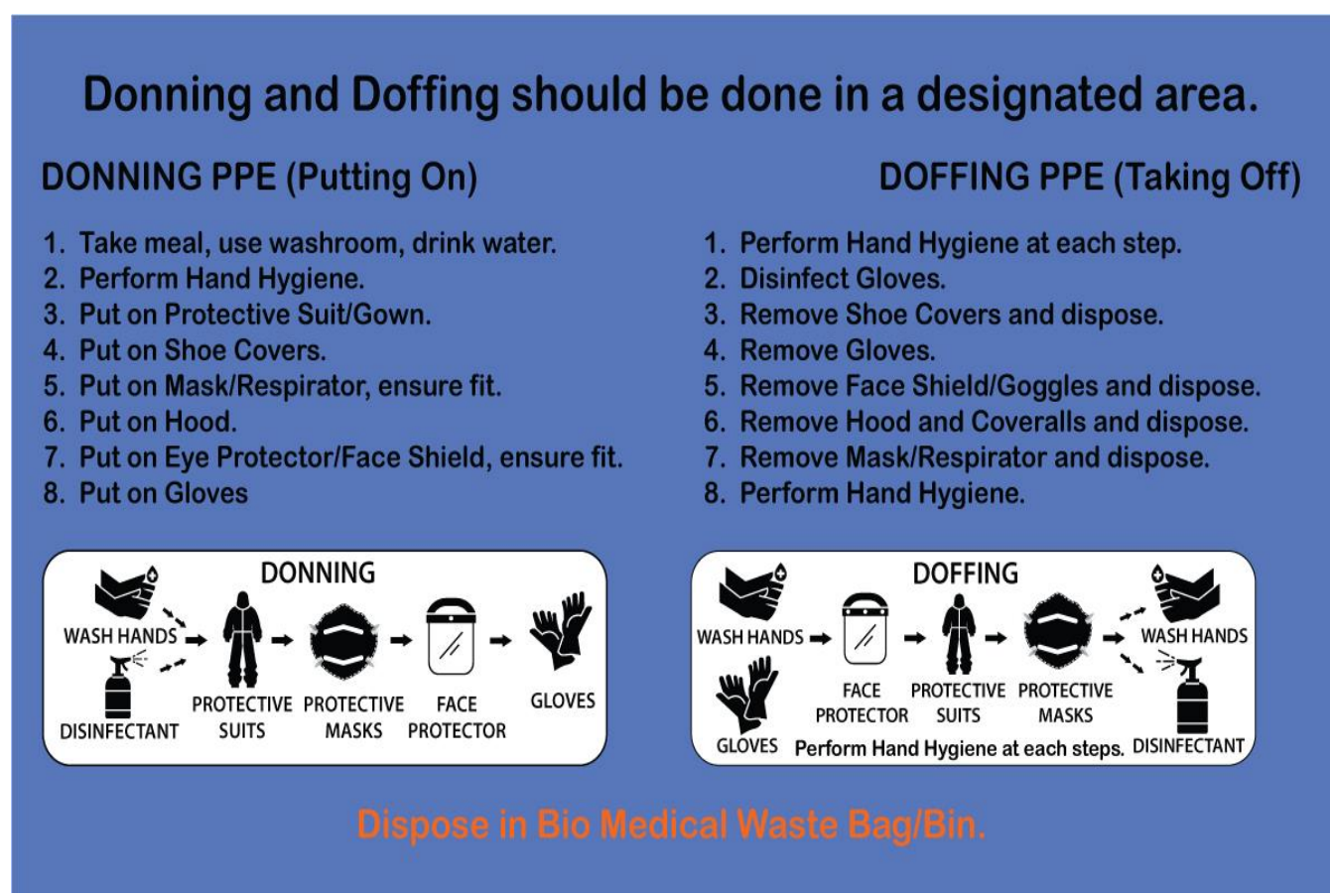

Fig 7. Directions for Donning and Doffing of PPEs 


\section{CONCLUSION}

Effective use of suitable PPE's may significantly protect HCWs from getting infected during their work. Different combinations of PPE's are required depending upon the nature of duties or level of exposure expected. HCWs must be made aware of the risk of contracting infections; importance, purpose and function of PPE's; just PPE's will not protect them; but the method to use it that will ensure; how, when and in what sequence PPE's have to be worn (Donning); precautions of removing PPE's (Doffing); and how the used PPE's have to be handled and disposed of after use. HCWs should also be made aware of how they could get infected even if they are wearing PPE's; what precautions they should take to prevent inadvertent selfinoculation. Suitable PPE coupled with Awareness based on correct information/ principles of infection control and disciplined Good Practices are the key to desired protection. For HCWs working with known/ suspected positive cases, PPE's should be of single-use, and suitably discarded after exposure before coming in contact with others. Even though not yet required by Indian Government's current quality standards, fabric and bodycoverall manufacturers should have their products tested for Resistance to Penetration by Blood-Borne Pathogens/Viral Penetration Resistance (IS 16545 or equivalent). Though it would be desirable to have products used in India to be of international standards, current standards set for body-coveralls could offer better protection than standard woven-fabric reusable gown. Users should be aware that India's coverall standard does not include testing for viral penetration, and material may not offer protection against liquids along with high pressure due to leaning, kneeling etc. and should exercise caution even with use of PPE. Body-coverall can be made more comfortable using fabrics that have the necessary levels of protection but better Water Vapor Transmission

\section{REFERENCES}

[1] https://www.sciencedirect.com/science/article/pii/S18760 34120303634\#bib0005

[2] https://www.sciencedaily.com/releases/2020/08/20080115 4203.htm

[3] de Almeida, Ronaldo André Castelo dos S. et al. 'Thermal Comfort and Personal Protective Equipment (PPE)'. 1 Jan. $2012: 4979-4982$.

[4] Akbar-Khanzadeh F, Bisesi MS, Rivas RD. Comfort of personal protective equipment. Appl Ergon. 1995 Jun;26(3):195-8. doi: 10.1016/0003-6870(95)00017-7. PMID: 15677018 .

[5] https://www.ndtv.com/india-news/from-zero-india-nowmanufactures-4-5-lakh-ppe-suits-a-day-to-fightcoronavirus-2231742

[6] https://health.economictimes.indiatimes.com/news/medica 1-devices/india-ramps-up-production-of-covid-19protective-gears-medical-equipment/75514109

[7] http://texmin.nic.in/covid/mot.php

[8] https://www.cdc.gov/infectioncontrol/spread/index.html

[9] https://www.who.int/medical devices/meddev_ppe/en/

[10] https://www.hse.gov.uk/toolbox/ppe

[11] https://www.britannica.com/biography/Ignaz-Semmelweis

[12] Thom W. Carl Flügge (1847-1923)--Leben und Werk eines grossen Hygienikers [Carl Flügge (1847-1923)--the life and work of a great public health scientist]. Z Gesamte Hyg. 1984 Dec;30(12):729-30. German. PMID: 6396979.

[13] https://en.wikipedia.org/wiki/List of_World_War_II unif orms and clothing rate for better compliance. This could make the product more expensive and as these would be of single use. A balance of comfort and cost will depend upon healthcare facility. Depending upon level of risk, substitutes of conjoint (one-piece) body-coveralls like the 'NavRakshak' designed by the Indian Navy, or bodysuits made of separate structures can be used to provide comfort. Depending upon the risk of exposure, single-use gowns made of suitable material offering liquid barrier protection could be used.

\section{ACKNOWLEDGMENTS}

RS is thankful for receiving training under the aegis of DBT Star College Scheme, Kirori Mal College. RS further acknowledges Dr. Q- Manufacturers of Body Coveralls for their valuable inputs regarding the equipment. RS is grateful to Ms. Ananyaa Pathak for guidance regarding graphic images. RS gratefully acknowledges the Biology Department at Vasant Valley School for fostering his interest.

\section{AUTHORS' CONTRIBUTIONS}

The participation of each author corresponds to the criteria of authorship and contributorship emphasized in the Recommendations for the Conduct, Reporting, Editing, and Publication of Scholarly work in Medical Journals of the International Committee of Medical Journal Editors. Indeed, all the authors have actively participated in the redaction, the revision of the manuscript, and provided approval for this final revised version.

\section{COMPETING INTERESTS}

The authors declare no competing interests with this case.

\section{FUNDING SOURCES}

None.

[14] https://www.vox.com/2020/4/10/21214980/coronaviruseconomy-jobs-ppe

[15] https://www.fibreglast.com/product/safety-incomposites/Learning Center

[16] https://www.sciencedirect.com/science/article/abs/pii/S01 69433215004596

[17] Kannan S, Shaik Syed Ali P, Sheeza A, Hemalatha K. COVID-19 (Novel Coronavirus 2019) - recent trends. Eur Rev Med Pharmacol Sci. 2020 Feb;24(4):2006-2011. doi: 10.26355/eurrev_202002 20378. PMID: 32141569

[18] Fan Y, Zhao K, Shi ZL, Zhou P. Bat Coronaviruses in China. Viruses. 2019 Mar 2;11(3):210. doi: 10.3390/v11030210. PMID: 30832341; PMCID: PMC6466186

[19] Decaro N, Lorusso A. Novel human coronavirus (SARSCoV-2): A lesson from animal coronaviruses. Vet Microbiol. 2020 May;244:108693. doi: 10.1016/j.vetmic.2020.108693. Epub 2020 Apr 14. PMID: 32402329; PMCID: PMC7195271

[20] Jain V, Yuan JM. Predictive symptoms and comorbidities for severe COVID-19 and intensive care unit admission: a systematic review and meta-analysis. Int J Public Health. 2020 Jun;65(5):533-546. doi: 10.1007/s00038-020-013907. Epub 2020 May 25. PMID: 32451563; PMCID: PMC7246302

[21] Jayaweera M, Perera H, Gunawardana B, Manatunge J. Transmission of COVID-19 virus by droplets and aerosols: A critical review on the unresolved dichotomy. Envirion Res. 2020 Sep;188:109819. doi: 
10.1016/j.envres.2020.109819. Epub 2020 Jun 13. PMID: 32569870; PMCID: PMC7293495.

[22] Naqvi AAT, Fatima K, Mohammad T, Fatima U, Singh IK, Singh A, Atif SM, Hariprasad G, Hasan GM, Hassan MI. Insights into SARS-CoV-2 genome, structure, evolution, pathogenesis and therapies: Structural genomics approach. Biochim Biophys Acta Mol Basis Dis. 2020 Oct 1;1866(10):165878. doi: 10.1016/j.bbadis.2020.165878. Epub 2020 Jun 13. PMID: 32544429; PMCID: PMC7293463.

[23] van Doremalen N, Bushmaker T, Morris DH, Holbrook MG, Gamble A, Williamson BN, Tamin A, Harcourt JL, Thornburg NJ, Gerber SI, Lloyd-Smith JO, de Wit E, Munster VJ. Aerosol and Surface Stability of SARS-CoV-
2 as Compared with SARS-CoV-1. N Engl J Med. 2020 Apr 16;382(16):1564-1567. doi: 10.1056/NEJMc2004973. Epub 2020 Mar 17. PMID: 32182409; PMCID: PMC7121658.

[24] Ying Liu, Albert A Gayle, Annelies Wilder-Smith, Joacim Rocklöv, The reproductive number of COVID-19 is higher compared to SARS coronavirus, Journal of Travel Medicine, Volume 27, Issue 2, March 2020, taaa021,

[25] https://advancedtextilessource.com/2018/09/10/understan ding-the-protective-textiles-market/

[26] https://www.hsimagazine.com/article/ppe-comfort-andcoolness-are-key 